\title{
Feto-maternal outcome in grand multipara
}

\author{
Rajib Roy*, Manisha Vernekar
}

Department of Obstetrics and Gynecology, ESI-PGIMSR, ESIC MC and Hospital, Joka, Kolkata, West Bengal, India

Received: 24 May 2017

Accepted: 29 May 2017

\author{
*Correspondence: \\ Dr. Rajib Roy, \\ E-mail: roy.rajib82@yahoo.in
}

Copyright: () the author(s), publisher and licensee Medip Academy. This is an open-access article distributed under the terms of the Creative Commons Attribution Non-Commercial License, which permits unrestricted non-commercial use, distribution, and reproduction in any medium, provided the original work is properly cited.

\begin{abstract}
Background: Grand multiparity has been considered as obstetric hazards both to the mother and foetus and thus, viewed with great caution. In present set up grand multiparity is associated with increased likelihood of feto-maternal complications.

Methods: The study was conducted to determine the feto-maternal outcome in grand multipara pregnancy.

Results: In present study, the prevalence of grand multipara was $0.72 \%$ out of 15196 deliveries in the period from September 2010 to august 2012. 79.1\% of the grand multipara women belonged to the age group of 31-40 years. A majority of the women were in Para 5. Most of the women had no antenatal care attendance. The highest prevalence of grand multipara women was seen among Muslim community (1.65\%). A majority (59.1\%) of the women were anemic. Caesarean section rate was $30.0 \%$ in our study. Post-partum hemorrhage was the most common complication encountered. $7.0 \%$ were macrosomic babies, whereas $8.7 \%$ were LBW babies. There were 10 perinatal deaths, birth asphyxia being the most important cause for the perinatal mortality. There were no maternal deaths.

Conclusions: Our study demonstrates that, there is increase in antenatal and intra-partum maternal complications like anaemia, hypertensive disorder, preterm labour, increase in the rate of caesarean section, PPH etc., leading to severe maternal morbidity. So, the study concludes that in grand multipara pregnancy, both the woman and the fetus are at a greater risk during pregnancy and labour. This risk can be effectively reduced with good antenatal care and delivery by trained personnel.
\end{abstract}

Keywords: Anaemia, Grand multipara, Maternal mortality, Obstructed labour, Post-partum haemorrhage, Uterine rupture

\section{INTRODUCTION}

Maternal and perinatal morbidity and mortality are major health problem in the developing countries like India. According to World Health Organization (WHO), over $99 \%$ of all maternal deaths occur in developing countries. ${ }^{1}$

All pregnancies and deliveries are potentially at risk. However, there are certain categories of pregnancies where the mother and the foetus are in a state of increased jeopardy and grand multiparity is one of them.
Grand multiparity, defined by the WHO as a pregnancy proceeded by five or more previous viable pregnancies after 24 weeks of gestation continues to challenge obstetric practice in the developing world. ${ }^{2}$ The overall incidence is between $10-30 \%$ with higher incidence in the Muslim countries where there is large family norm and poor acceptance of family planning methods, while in the developed countries grand multiparity is becoming rare, $3-4 \%$ of all births. ${ }^{3,4}$

The historical origin of the term grand multiparity is uncertain, and a number of definitions have been used. ${ }^{5}$ 
The term Grand multipara introduced by Solomon's in 1934, describes a woman who has undergone five or more deliveries to what he called the dangerous multipara. ${ }^{6}$ The International Federation of Gynaecology and Obstetrics (1993) define grand multiparity as delivery of the fifth to ninth infant, whereas delivery of the ten (or more) are considered being greatgrandmultiparas. ${ }^{7}$

Solomon's pointed out that maternal mortality was higher in grand multipara, which number increased steadily as parity became greater.

The problem of grand multipara in the developing countries is compounded by a high prevalence of low socioeconomic status, poor female literacy, and social deprivation, as well as inadequate performance of family planning initiatives. ${ }^{8}$

The complications of pregnancy in the grand multipara are increased risk of abortions, multiple pregnancy, abruptio placenta, placenta praevia, malpresentation, anaemia, post-partum haemorrhage, macrosomic babies, preterm labour etc. The chance of caesarean section is high due to malpresentation, malposition, cephalo pelvic disproportion (CPD) etc. ${ }^{9}$ As the situation is seen in the older women, medical as well as gynaecological conditions as seen to complicate these pregnancies more than those of lower parity.

In labour, there is failure of descent of the presenting part during the first stage of labour and arrest of cervical dilation leading to high caesarean section rate. ${ }^{10}$ The perinatal morbidity and mortality in grand multipara is found to be high. ${ }^{9}$ However, there is still controversy as some studies reported that grand multiparous women don't have an increased incidence of obstetric complications particularly in developed countries where there is satisfactory health care conditions. ${ }^{7,11}$

During the last few decades the proportion of grand multipara has decreased in most developed countries because of a dramatic change in the practice of contraception and the acceptance of family planning methods. ${ }^{6}$

In present set, up grand multiparity is associated with increased likelihood of maternal and perinatal complications. Therefore, it is planned to estimate the prevalence of grand multipara pregnancy, to find out the different risk factors associated with the grand multipara pregnancy and to determine the maternal and neonatal outcome in grand multipara women in Regional Institute of Medical Sciences, Imphal.

\section{METHODS}

The study was cross-sectional study carried out in the Department of Obstetrics and Gynaecology, Regional Institute of Medical Sciences, Imphal, Manipur, for a period of one and a half calendar year with effective from September 2010 to February 2012. All the cases of grand multipara women (parity $\geq 5$ ) that have fulfilled the definition as per the study, with completed $\geq 24$ weeks of gestation were included in the study. The study was conducted after the approval from the Institutional Ethical Committee, RIMS, Imphal.

The variables used as determinants for the maternal outcome were age; parity, socio-economic status, literacy, religion, habitat, period of gestation, obstetrical history, age of marriage; haemoglobin level etc. and variables for foetal outcome were Apgar score, birth weight, maturity, congenital anomalies, sex etc.

\section{Statistical analysis}

The observation of the study was recorded in a SPSS 16 version programme. The maternal and neonatal outcomes were analysed using descriptive test like mean, range and percentages and Chi-square test. $\mathrm{P}<0.05$ was considered to be a statistical significance.

\section{RESULTS}

During the study period of 18 months (September 2010February 2012), the total number of deliveries conducted was 15,196 deliveries, out of which, 110 were grand multiparas giving the prevalence of grand multipara as $0.72 \%$.

The mean age of grand multiparous woman was $35.12 \pm 3.99$ years. Most of the grand multipara women were found frequent with increasing age, $79.1 \%$ were between age group of 31-40 years.

Table 1: Parity wise distribution of grand multipara women $(\mathbf{n}=110)$.

\begin{tabular}{|lll|}
\hline Parity & No. of cases & Percent \\
\hline 5 & 70 & 63.6 \\
\hline 6 & 24 & 21.8 \\
\hline 7 & 7 & 6.4 \\
\hline 8 & 8 & 7.3 \\
\hline 9 & 1 & 0.9 \\
\hline
\end{tabular}

The mean parity was 5.6 \pm 0.96 , with parity range of 5-9 as shown in Table 1. The majority of the women belonged to Para $5(63.6 \%)$. The highest parity seen was Para 9 in one woman. No family planning methods were adopted by most of the grand multipara women. Analysis of ANC showed a distinctly poorer attendance, with $61.8 \%$ documenting absolutely no ANC and only $38.2 \%$ with having ANC visits. Majority of the women belonged to rural area and hilly regions $(77.3 \%)$ with poor access to health care facilities and family planning initiatives. About $60 \%$ were from poor class and $40 \%$ were from middle class. Thus, this shows increase prevalence of grand multiparity in lower socio-economic group. Education was another main factor for the increasing 
incidence of grand multiparity. There were $54(49.1 \%)$ illiterate women, $42(38.2 \%)$ studied upto matriculate level and only $2(1.8 \%)$ were graduated. Majority of them were house wives $(76.4 \%)$.

Due to larger population of Hindu community in our study centre, each community were analysed separately according to the number of deliveries, it showed that the Muslim community were having high prevalence of grand multiparas $(1.65 \%)$, followed by Christian $(1.43 \%)$ and Hindu $(0.47 \%)$. These findings were statistically significant $(\mathrm{P}=0.000)$. Grand multipara groups were seen with predominance of early marriage. Large proportions were between 16-20 years $(43.6 \%)$ at the time of marriage, $7.3 \%$ were < 15 years. Majority of grand multiparous women belonged to the gestation age 37-42 weeks $(90 \%)$. There were $3(2.7 \%)$ women crossed $>42$ weeks and $8(7.3 \%)$ preterm pregnancy.

In present study, anaemia was very high $(59.1 \%)$, out of which; $9(8.2 \%)$ were having severe anaemia $(\mathrm{Hb} \leq 7 \mathrm{gm}$ $\%)$. Also, anaemia in pregnancy was the most common antepartum complication followed by PIH/pre-eclampsia, oligohydramnios, preterm pregnancy, APH, PROM, malpresentation, etc.

\section{Intra partum events}

Most of the women delivered within 6 hours $(78.2 \%)$. The mean duration of labour was $4.8 \pm 4.613$ hours; with maximum duration seen was 27 hours. Most of the women delivered vaginally without episiotomy (50.9\%). A higher caesarean rate was noted $(30.0 \%)$, out of which; $26(23.6 \%)$ were emergency and $7(6.4 \%)$ were elective basis. The incidence of instrumental delivery was $9.1 \%$. Laparotomy was performed in two women for uterine rupture. The most common indication for caesarean section was Cephalo pelvic disproportion (42.5\%), followed by foetal distress (18.2\%), malpresentation/malposition (12.1\%), etc.
Table 2: Maternal morbidity in grand multipara women $(n=110)$.

\begin{tabular}{|lll|}
\hline Morbidity & Number & Percent \\
\hline Anaemia & 65 & 59.1 \\
\hline PPH & 31 & 28.2 \\
\hline $\begin{array}{l}\text { PIH/pre- } \\
\text { eclampsia/eclampsia }\end{array}$ & 16 & 14.5 \\
\hline APH & 7 & 6.3 \\
\hline Shock & 5 & 4.5 \\
\hline ICU admission & 2 & 1.8 \\
\hline Uterine rupture & 2 & 1.8 \\
\hline Uterine inversion & 1 & 0.9 \\
\hline
\end{tabular}

Malpresentation/malposition (6.3\%) was the most common intrapartum complication encountered followed by prolonged 2nd stage of labour (3.6\%), obstructed labour $(2.7 \%)$, rupture uterus $(1.8 \%)$, etc.

Primary PPH was the most common post-partum complication seen $(24.54 \%)$, followed by perineal tear $(12.7 \%)$, shock $(4.5 \%)$, retained placenta $(3.6 \%)$ and secondary PPH (3.6\%), respectively. There was one case of acute uterine inversion which was repositioned immediately.

Anaemia was the most common risk for maternal morbidity followed by PPH, PIH/preeclampsia/eclampsia, APH, etc as shown in Table 2. The maternal mortality during the study period was $85.54 / \mathrm{lac}$ women from the total deliveries. There were no maternal deaths in grand multiparas women.

\section{Neonatal outcome}

There were 114 total babies delivered. There were 10 perinatal deaths. Congenital anomalies were seen in 18 babies.

Table 3: Association of parity groups and pregnancy event $(n=110)$.

\begin{tabular}{|c|c|c|c|c|}
\hline Characteristic & & Parity 5, n (\%) & Parity 6-9 n (\%) & $P$ value \\
\hline \multirow{4}{*}{ Hemoglobin (gm\%) } & $\leq 7$ & $2(22.2)$ & $7(77.8)$ & \multirow{4}{*}{0.060} \\
\hline & $7.1-8$ & $5(62.5)$ & $3(37.5)$ & \\
\hline & $8.1-10$ & $33(68.8)$ & $15(31.2)$ & \\
\hline & $>10$ & $30(66.7)$ & $15(33.3)$ & \\
\hline \multirow{4}{*}{ Mode of delivery } & NVD & $30(50.8)$ & $29(49.2)$ & \multirow{4}{*}{0.009} \\
\hline & Operative* & $29(85.3)$ & $5(14.7)$ & \\
\hline & Instrumental & $8(80)$ & $2(20)$ & \\
\hline & Abnormal** & $3(42.9)$ & $4(57.1)$ & \\
\hline \multirow[b]{3}{*}{ Birth weight (Kg) } & $<2.5$ & $5(62.5)$ & $3(37.5)$ & \multirow{3}{*}{0.35} \\
\hline & $2.5-4$ & $58(61.7)$ & $36(38.3)$ & \\
\hline & $>4$ & $7(87.5)$ & $1(12.5)$ & \\
\hline
\end{tabular}

*operative- LSCS and laparotomy, in which 2 cases of laparotomy for uterine rupture was performed in Para 5 group, **breech, twin delivery 
Most of the babies weighed between 3.5-4.0 Kg (37.8\%). In present study, 8 babies were macrosomic $(>4 \mathrm{Kg})$ and 10 were $\mathrm{LBW}(<2.5 \mathrm{Kg})$.

Severe anaemia was more frequent among the higher parity (Para 6-9). Association of mode of delivery and parity groups were found significant $(\mathrm{P}<0.01)$ as shown in Table 3. Association of birth weight with the parity was also found to be significant. As the parity increases, macrosomia becomes frequent.

\section{DISCUSSION}

The issue of grand multiparity has gained importance in past few years. Due to associated risk of grand multiparity, maternal and fetal morbidity and mortality are also increased in this woman. ${ }^{12}$ Grand multiparity is now less frequently encountered in Western obstetric practice because of increased use of family planning methods. $^{13}$

The prevalence of grand multiparity in our study was $0.72 \%$, while it has been found as $2.2 \%$ as reported by $\mathrm{S}$ Munim et al which is higher compared to present study. ${ }^{14}$ The low prevalence of grand multipara in present study center might be due to adoption of family planning methods, National Rural Health Mission (NRHM) propaganda, awareness regarding high parity related complications, positive attitude and Government encouragement towards small family norm, maximum deliveries at first referral unit, etc.

In other way, the low prevalence in this study might be a reflection of the lack of antenatal care attendance since we documented as $61.8 \%$ unbooked women in present study. This could be because of time management, limited resources in the family as the majority of the women belonged to the low socio-economic class $(60 \%)$ and negative perception resulting from previous pregnancies. Another reason may be due to belonging to rural area with poor access to the health care facilities.

About $79.1 \%$ grand multipara women were between 3140 years which was found slightly higher than the figure of $74.34 \%$ and $76.0 \%$ as reported by Methal A et al and Rayamajhi $\mathrm{R}$ et al, respectively., ${ }^{2,3}$ Advanced maternal age is an independent risk factor for a number of antenatal medical disorder which potentially influence both maternal and neonatal morbidity and mortality. ${ }^{15}$

The present study revealed that grand multipara had low rate of ANC attendance (61.8\%), a figure comparable to those reported by Ogendengbe OK et al (57.8\%) and $56.6 \%$ by Rayis DA et al. ${ }^{11,16}$

Regarding the parity distribution, in present study, $63.6 \%$ of women were Para 5, however, D'souza K et al observed Para 7 as the maximum parity (33\%). ${ }^{5}$ Among present grand multiparas, the highest parity was 9 , seen in one woman. Rural residents constituted $77.3 \%$ of the grand multipara women compared to $60.38 \%$ as reported by Rayamajhi $\mathrm{R}$ et al. ${ }^{3}$

After analysing each community separately according to the total number of deliveries, it showed that the Muslim community were having high prevalence of grand multiparas (1.65\%), followed by Christian (1.43\%) and Hindu $(0.47 \%)$. This finding was highly statistically significant $(\mathrm{P}=0.000)$. Early marriage, large family norm, illiteracy and poor acceptance of modern family planning methods could have accounted for higher prevalence among Muslim women. D'Souza K et al reported higher prevalence among the Muslim community (97\%). ${ }^{5}$

It was observed in present study that $60 \%$ belonged to the low socioeconomic status, also reported by Rizwan $\mathrm{N}$ et al, which accounts for the delay in intervention and poor prognosis in the event of complications in this group. ${ }^{10}$ Majority of the women were literate $(50.9 \%)$ whereas illiteracy was seen in $49.1 \%$. These findings were contradictory with that of D'souza $\mathrm{K}$ et $\mathrm{al}^{5}$ in which illiteracy was found among $87 \% .^{5}$

The results of the present study revealed early marriage with mean age of marriage of $20.75 \pm 3.32$ years which was lower than $29.72 \pm 2.09$ years reported by Ohonsi AO et al. ${ }^{8}$ Pregnancy complications were more prevalent in this study, probably because of older maternal age groups.

Furthermore, it has been shown that, anemia in pregnancy was common. It was revealed that $59.1 \%$ of women had anaemia which was similar to a study done by D'souza $\mathrm{K}$ et $\mathrm{al}^{5}(59 \%)$. Rizwan $\mathrm{N}$ et al represented highest incidence of anaemia (90\%) and the lowest incidence was reported by Irvine et al (22\%). ${ }^{10,17}$ Hypertensive disorders in pregnancy were found in $14.5 \%$ of women in this study (eclampsia $0.9 \%$ and pre-eclampsia/PIH 13.6\%) which was lower than reported by Munium et al $(15.4 \%){ }^{18}$

In present study, twin pregnancy rate was $3.6 \%$, almost similar to that of Mutihir JT (3.2\%) and Begum S $(3.83 \%) .{ }^{12,19}$ Majority of the women delivered within $<6$ hours of labour $(78.2 \%)$ with the mean duration of 4.80 hours. The duration of the active phase of labour increases after the fourth child as suggested by Lyrenas S. ${ }^{20}$

Vaginal delivery was seen in $53.6 \%$ women, out of which, $2.7 \%$ required episiotomy. This finding was similar to that of Begum $\mathrm{S}(50 \%) .{ }^{12}$ However, instrumental (vacuum) delivery was found to be $9.1 \%$ compared to a lower rate of $3.5 \%$ in Munim S et al thus, decreasing the caesarean section rate in this study. ${ }^{14}$ The caesarean section rate was $30.0 \%$, out of which $6.4 \%$ was elective. Shahida SM et al observed caesarean section rate as $32 \%$. The higher caesarean section rate could be explained by CPD which attributed to macrosomia and pelvic contractures in grand multipara women. ${ }^{21}$ 
Uterine rupture was seen in 2 women (1.8\%), one following instrumental delivery and another unscarred uterus rupture, both requiring laparotomy. Benecke $\mathrm{C}$ et al also reported 2 cases of rupture uterus $(1.9 \%) .{ }^{22}$ Postpartum haemorrhage was the most common post-partum complication $(28.14 \%$ ) which was mostly due to uterine atony. This figure was comparable to $19 \%$ of Rizwan $\mathrm{N}$ et al. ${ }^{10}$

There was 4(3.6\%) of retained placenta in which manual removal was done. The figure was $2.6 \%$ as reported by Humphrey M. ${ }^{23}$ There was one case of retained twin. Maternal morbidity in present study was largely due to antepartum/intra partum complications like anaemia, primary PPH and hypertensive disorder. About $73.6 \%$ had hospital stay for around 5 days. Fortunately, there were no maternal deaths in present study. This could be due to proper diagnosis and early intervention of the lethal maternal morbidity. Similary, D'souza K et al also had no maternal deaths. ${ }^{5}$ There were 15 maternal deaths as reported by Rayis D et al. ${ }^{11}$

Macrosomia is responsible for intrapartum complications like birth trauma, shoulder dystocia, birth asphyxia, obstructed labour and increased rate of instrumental delivery. There was 7\% fetal macrosomia and $8.7 \%$ of LBW babies. Yasmeen $\mathrm{L}$ et al documented $12 \%$ of macrosomia and $6 \%$ of LBW babies. ${ }^{24}$ The incidence of shoulder dystocia was $3.6 \%$ mainly due to fetal macrosomia in contrast with $0.42 \%$ by Nordin NM et al. ${ }^{25}$ We observed $15.8 \%$ of congenital anomalies in the new born. However, Yasir R et al found $4 \%$ and Rizwan $\mathrm{N}$ et al reported no congenital anomalies. ${ }^{10,15}$

In present study, there were 10 perinatal deaths out of 114 babies born giving the PMR as 87.72/1000 live births, while Eze J N et al reported PMR as 73.4/1000 deliveries. $^{26}$ The major contributing factor for the perinatal mortality was birth asphyxia (3.6\%), serious congenital anomalies (2.7\%), prematurity (2.7\%) and abruptio placenta and rupture uterus $(0.9 \%)$ and lack of advance Neonatal Intensive Care Unit in our study center. D'souza $\mathrm{K}$ et al documented 12 perinatal deaths in their study. ${ }^{5}$

The rate complications such as anaemia, hypertensive disorder, placenta previa, preterm labour, post-partum haemorrhage, obstructed labour, macrosomic babies, and perinatal deaths, all were higher in our study in comparison to other studies, which were reviewed. Currently, studies from developed countries are increasingly reporting fewer complications during pregnancy and labor among grand multiparas and obstetrical complications there among the grand multiparas are now independently associated with progressive maternal age. Hence, in these countries where the socioeconomic status of women is high and there is high standard of perinatal care, high parity is no longer considered a risk marker for obstetric complications. However, as shown in this study, grand multiparity is not so common in our center, but still it is associated with high maternal morbidity, perinatal morbidity and mortality. Hence, to reverse this trend, there must be widespread community enlightenment on the importance of limitation of family size and number of child births, should be encouraged to initiate ANC in health facilities where there is provision for emergency obstetric care early in pregnancy. There is need for community based studies in our environment accessing the knowledge and attitude of women with high parity towards contraception.

\section{CONCLUSION}

Ever since Solomon's (1934) drew world's attention to what he called the dangerous multipara, emphasizing grand multiparity as a clinical entity in its own right and for several decades grand multiparity has been considered as an obstetric hazard both to the mother and fetus and thus, viewed with great caution.

The combination of grand multiparity and the lack of antenatal care seem to negatively affect the pregnancy outcome. Thus, they should be considered as high-risk pregnancies and should be treated with extra care.

Present study demonstrates that, there is increase in antenatal and intra-partum maternal complications like anaemia, hypertensive disorder, preterm labour, increase in the rate of caesarean section etc. and the incidence of postpartum haemorrhage in these women, leading to severe maternal morbidity.

So, the study concludes that in grand multipara pregnancy, both the woman and the fetus are at a greater risk during pregnancy and labour. This risk can be effectively reduced with good antenatal care and delivery by trained personnel. Emphasis on health education, provision of accessible and effective National Family Planning Initiatives as well as awareness of the adverse impact of high parity on obstetric performances should be intensified in our community.

\section{ACKNOWLEDGMENTS}

Authors express sincere gratitude to teachers and guide in the Deptartment of Obstetrics and Gynaecology, RIMS, Imphal for their constant source of inspiration and guidance. Authors are also grateful to all patients who have co-operated during present study.

\section{Funding: No funding sources}

Conflict of interest: None declared

Ethical approval: The study was approved by the Institutional Ethics Committee

\section{REFERENCES}

1. Nour NM. An introduction to maternal mortality. Rev Obstet Gynecol. 2008;1(2):77-81. 
2. Methal A, Rubaee A. Risk of grand multiparity on both mother and fetus. Med J Babylon. 2005;2(3):288-94.

3. Rayamajhi R, Thapa M, Pande S. The challenge of grand multiparity in obstetric practice. Kathmandu University Med J. 2006;4(1):70-4.

4. Roman H, Robillard PY, Verspyck E, Hulsey TC, Marpeau L, Barau G. Obstetric and neonatal outcome in grand multiparity. Obstet Gynecol. 2004;103(6):1294-9.

5. D'souza K, Monteiro FNP, Jayaprakash K, Bhagavath P, Krishnan S. Spectrum of grand multiparity. J Clini Diagnos Res. 2011;5(6):1247-50.

6. Hinkula M, Kauppila A, Näyhä S, Pukkala E. Causespecific mortality of grand multiparous women in Finland. Am J Epidemiol. 2006;163(4):367-73.

7. Bugg GJ, Atwal GS, Maresh M. Grandmultiparae in a modern setting. BJOG. 2002;109:249-53.

8. Ohonsi AO, Ashini AO. Grand multiparity: Obstetric performance in Aminu Kano teaching hospital, Kano, Nigeria. Nigerian J Clini Practice. 2011;14(1):6-9.

9. Shahid R, Mushtaq M. Complications of grand multiparity. Pakistan Armed Forces Med J. 2009;4:15

10. Rizwan N, Parveen G, Abbasi RM. Frequency of grand multiparity and its feto-maternal outcome at Liaquat University Hospital, Hyderabad. Isra Med J. 2009;1(2): 49-53.

11. Rayis D A, Ali AA, Abbaker A, Adam I. Maternal and perinatal outcomes of grand multiparity in Kassala hospital, eastern Sudan. Khartoum Med J. 2011;4(1):554-7.

12. Begum S. Age and parity related problems affecting outcome of labour in grand multiparas. Pak J Med Res. 2003;42(4):179-84.

13. Rizk D E E, Khalfan M, Ezimokhai M. Obstetric outcome in grand multipara in the United Arab Emirates: A case control study. Arch Gynecol Obstet. 2001;264:194-8.

14. Munim S, Rahbar M H, Rizvi R M, Mustaq N. The effect of grand multiparity on pregnancy related complications: The Aga Khan University Experience. J Pak Med Ass. 2000;50:54-9.
15. Yasir R, Perveen F, Ali L, Perveen S, Tayyab S. Grand multiparity- still an obstetric risk for developing countries. J Modern Med Dent Sci. 2010;16(2):264-7.

16. Ogedengbe OK, Ogunmokun AA. Grand multiparity in Lagos, Nigeria. Niger Postgrad Med J. 2003;10(4):216-9.

17. Irvine LM, Otigbah C, Crawford A, Setchell ME. Grand multiparity- an obstetric problem in Great Britain in the 90's? J Obstet Gynaecol. 1996;16(4):217-23.

18. Samueloff A, Schimmel MS, Eidelman Al. Grand multiparity. Is it a perinatal risk? Clin Perinatol. 1998;25(3): 529-38.

19. Mutihir JT. Obstetric outcome of the grand multipara in Jos, Nigeria. J Med Tropics. 2005;7(1):14-20.

20. Lyrenas S. Labor in the grand multipara. Gynecol Obstet Invest. 2002;53(1):6-12.

21. Shahida SM, Islam MA, Begum S, Hossain MA, Azam MS. Maternal outcome of grand multipara. Mymensingh Med J. 2011;20(3):381-5.

22. Benecke C, Siebert TI, Kruger TF, Grove D. Antepartum and intrapartum complications in grand multiparous patients compared with multiparous patients at Tygerberg Hospital. South African J Obstet Gynaecol. 2005;11(1):14-6.

23. Humphrey MD. Is grand multiparity an independent predictor of pregnancy risk? Med J Aust. 2003;179:294-6.

24. Yasmeen L, Rasheed T, Syed S. Is grand multiparity still a risk factor for obstetric complications? Ann Pak Inst Med Sci. 2010;6(1):58-61.

25. Nordin NM, Fen CK, Isa S, Symonds EM. Is grandmultiparity a significant risk factor in this new millennium? Malaysian J Med Sci. 2006;13(2):5260.

26. Eze JN, Okaro JM, Okafor MH. Outcome of pregnancy in the grand multipara in Enugu, Nigeria. Trop J Obstet Gynecol. 2006;23(1):8-11.

Cite this article as: Roy R, Vernekar M. Fetomaternal outcome in grand multipara. Int J Reprod Contracept Obstet Gynecol 2017;6:2846-51. 